\title{
ON BOUNDEDNESS OF INTEGRAL MEANS OF BLASCHKE PRODUCT LOGARITHMS
}

\author{
YA.V. VASYLKIV, A.A. KONDRATYUK, S.I. TARASYUK \\ Lviv National University after Ivan Franko \\ Universytetska 1, Lviv 79000, Ukraine \\ E-mail: j_vasylkiv@franko.lviv.ua; kond@franko.lviv.ua
}

Received November 30 2001; revised July 82003

\section{ABSTRACT}

Using the Fourier series method for the analytic functions, we obtain a result characterizing the behaviour of the integral means of Blaschke product logarithms. Namely, if the zero counting function $n(r, B)$ of the Blaschke product $B$ satisfies the condition

$$
n(r, B)=O\left((1-r)^{-1 / q} l(r)\right), \quad r \rightarrow 1, \quad q>1,
$$

where $l$ is a positive function on $(0,1)$ such that

$$
\int_{0}^{1} \frac{l(t)}{1-t} d t<+\infty
$$

then the $q$-integral mean $m_{q}(r, \log B)=\left\{\frac{1}{2 \pi} \int_{0}^{2 \pi}\left|\log B\left(r e^{i \theta}\right)\right|{ }^{q} d \theta\right\}^{1 / q}$ is bounded on $(0,1)$, where $\log B$ is a branch of the logarithm of $B$.

Key words: Fourier series, anlytic functions, Blaschke product logarithms

\section{INTRODUCTION}

Let $D$ be the unit disk centered at the origin, $\left\{a_{\nu}\right\}$ be a sequence of points $a_{\nu}=\left|a_{\nu}\right| e^{i \alpha_{\nu}}$ from $D, a_{\nu} \neq 0$, such that

$$
\sum_{\nu=1}^{+\infty}\left(1-\left|a_{\nu}\right|\right)<+\infty
$$


and

$$
B(z)=\prod_{\nu=1}^{+\infty} \frac{\bar{a}_{\nu}}{\left|a_{\nu}\right|} \frac{a_{\nu}-z}{1-\bar{a}_{\nu} z}, \quad z \in D
$$

be the Blaschke product. Let us denote by $D^{*}$ the domain

$$
D^{*}=D \backslash \cup_{\nu=1}^{+\infty}\left[a_{\nu}, e^{i \alpha_{\nu}}\right)
$$

Let us consider the function

$$
\log B(z)=\log B(0)+\int_{0}^{z} \frac{B^{\prime}(\xi)}{B(\xi)} d \xi, \quad z \in D^{*}
$$

where the integral is taken along the segment $[0, z]$ :

$$
\log B(0)=\log |B(0)|=\sum_{\nu=1}^{+\infty} \log \left|a_{\nu}\right|=\int_{0}^{1} \log t d n(t, B)
$$

and $n(t, B)$ is the number of zeros of the function $B(z)$ in the closed disk of radius $t, 0<t<1$, centered at the point $z=0$.

It follows from the Blaschke condition (1.1) [4] that

$$
(1-t) n(t, B)=o(1), \quad t \rightarrow 1
$$

Then integrating by parts in (1.2) we get

$$
\log B(0)=-\int_{0}^{1} n(t, B) t^{-1} d t
$$

Let also

$$
m_{q}(r, \log B)=\left\{\frac{1}{2 \pi} \int_{0}^{2 \pi}\left|\log B\left(r e^{i \theta}\right)\right|^{q} d \theta\right\}^{1 / q}, \quad 1 \leq q<+\infty, \quad 0<r<1,
$$

be the integral means of the logarithm of the Blaschke product.

A. Zygmund [9] stated the following problem: to describe such sequences of zeros $\left\{a_{\nu}\right\}$, that the function $m_{2}(r, u), u=\log |B|$ be bounded on $(0,1)$.

By using the Fourier series method for the analytic functions $[6 ; 10 ; 11]$ G. R. MacLane and L. A. Rubel [9] solved this problem in 1969. In particular, they found that the condition

$$
n(r, B)=O\left((1-r)^{-1 / 2}\right), \quad r \rightarrow 1
$$


is sufficient for achieving the relation

$$
m_{2}(r, u)=O(1), \quad r \rightarrow 1,
$$

while being also necessary for the Blaschke products $B(z)$ with zeros concentrated at the finite system of beams. Some results characterizing the behaviour of integral logarithmic means of order $q, 1<q<+\infty$, of Blaschke products were obtained by C. N. Linden $[7 ; 8]$.

Recently, A. A. Kondratyuk and V. V. Yeyko [12] stated that for arbitrary $q \in(1,+\infty)$ there is a constant $A_{q}>0$ such that

$$
(1-r)^{1 / q^{\prime}} m_{q}(r, u) \leq A_{q} \int_{r}^{1} n(t, B) t^{-1} d t, r \in(0,1), 1 / q+1 / q^{\prime}=1 .
$$

\section{MAIN PROBLEM}

The main problem we solve is to find the conditions under which the Lebesgue means of the logarithm of the Blaschke product modulus and some branch of its argument are bounded.

\section{Proof of the main result}

Here, the following result will be established.

Theorem 2.1. Let $B(z)$ be the Blaschke product, $1<q<+\infty$. If

$$
n(r, B)=O\left((1-r)^{-1 / q} l(r)\right), \quad r \rightarrow 1,
$$

where $l(r)$ is some positive on $(0,1)$ function, such that

$$
\int_{0}^{1}(1-t)^{-1} l(t) d t<+\infty
$$

then the function $m_{q}(r, \log B)$ is bounded on $(0,1)$.

Proof. Denote by $\widetilde{u}\left(r e^{i \theta}\right)=(H * u)\left(r e^{i \theta}\right)$ for any fixed $r \in(0,1)$ the convolution of Hilbert's distribution [2]

$$
H=\sum_{k=-\infty}^{+\infty}-i(\operatorname{sign} k) e^{i k \psi}, \quad \operatorname{sign} 0=0
$$

with the function $u\left(r e^{i \theta}\right)=\log \left|B\left(r e^{i \theta}\right)\right|$, i.e.

$$
c_{k}(r, \widetilde{u})=-i(\operatorname{sign} k) c_{k}(r, u), \quad k \in Z,
$$


where

$$
c_{k}(r, u)=\frac{1}{2 \pi} \int_{0}^{2 \pi} u\left(r e^{i \theta}\right) e^{-i k \theta} d \theta, \quad k \in Z
$$

Let also

$$
p\left(r e^{i \theta}\right)=\int_{0}^{r} \frac{d t}{t} \int_{|a| \leq t} P\left(r, t e^{i(\theta-\alpha)}\right) d \mu(a), a=|a| e^{i \alpha}, 0<r<1
$$

where $P(r, w)=\operatorname{Re}\left[(r+w)(r-w)^{-1}\right]$ is the Poisson kernel, $\mu(a)=\sum_{\nu} \delta(a-$ $\left.a_{\nu}\right), \delta(\xi)$ is the Dirac measure. According to [5]

$$
\begin{aligned}
& c_{0}(r, \log B)=c_{0}(r, u), \\
& c_{k}(r, \log B)=\gamma_{k} r^{k}+\int_{0}^{r}\left(\frac{r}{t}\right)^{k} \frac{n_{k}(t, B)}{t} d t, \quad k \in N, \\
& c_{-k}(r, \log B)=\int_{0}^{r}\left(\frac{t}{r}\right)^{k} \frac{n_{-k}(t, B)}{t} d t, \quad k \in N,
\end{aligned}
$$

where $\gamma_{k}$ are determined from the development

$$
\log B(z)=\log B(0)+\sum_{k=1}^{+\infty} \gamma_{k} z^{k}
$$

in the vicinity of the point $z=0$, and

$$
n_{k}(r, B)=\int_{|a| \leq r} e^{-i k \alpha} d \mu(a), \quad k \in Z, \quad n_{0}(r, B)=n(r, B)
$$

Taking into account the relation (2.4) and the development

$$
P\left(r, t e^{i(\theta-\alpha)}\right)=\sum_{k=-\infty}^{+\infty}\left(\frac{t}{r}\right)^{|k|} e^{i k(\theta-\alpha)}
$$

we will get

$$
\begin{gathered}
c_{k}(r, p)=\frac{1}{2 \pi} \int_{0}^{2 \pi} p\left(r e^{i \theta}\right) e^{-i k \theta} d \theta=\int_{0}^{r} \frac{d t}{t} \int_{|a| \leq t}\left(\frac{t}{r}\right)^{|k|} e^{-i k \alpha} d \mu(a) \\
=\int_{0}^{r}\left(\frac{t}{r}\right)^{|k|} \frac{n_{k}(t, B)}{t} d t, \quad k \in Z .
\end{gathered}
$$


The relations (2.3), (2.5) and (2.6) as well as the formulas for the Fourier coefficients $c_{k}(r, u), k \in Z$, (see [9], or [6;10;11]) will give us the equality

$$
c_{k}(r, \log B)=c_{k}(r, u)+i c_{k}(r, \widetilde{u})-i c_{k}(r, \widetilde{p}),
$$

which will hold for any $k \in Z, r \in(0,1)$, i.e.

$$
\log B=u+i \widetilde{u}-i \widetilde{p}
$$

Then, by applying the Minkowski inequality, we will get for the arbitrary $q \in(1,+\infty), r \in(0,1)$

$$
m_{q}(r, \log B) \leq m_{q}(r, u)+m_{q}(r, \widetilde{u})+m_{q}(r, \widetilde{p}) .
$$

By virtue of the theorem of M. Riesz [1] we obtain

$$
m_{q}(r, \widetilde{u})+m_{q}(r, \widetilde{p}) \leq C_{q}\left[m_{q}(r, u)+m_{q}(r, p)\right],
$$

where $C_{q}=\operatorname{tg} \frac{\pi}{2 q}$, if $1<q \leq 2$ or $C_{q}=\operatorname{ctg} \frac{\pi}{2 q}$, if $2 \leq q<+\infty$. Taking into consideration the inequalities (2.7) and (1.3) we find that

$$
m_{q}(r, \log B) \leq A_{q}\left(1+C_{q}\right)(1-r)^{-1 / q^{\prime}} \int_{r}^{1} n(t, B) t^{-1} d t+C_{q} m_{q}(r, p),
$$

where $1 / q+1 / q^{\prime}=1$.

To estimate the last term on the right-hand side of (2.8) let us apply the integral Minkowski inequality ([3], p.24) twice as well as substituting the variable $t=r \tau$. Then, we will get

$$
\begin{aligned}
m_{q}(r, p) & \leq \int_{0}^{r} \frac{d t}{t}\left\{\frac{1}{2 \pi} \int_{0}^{2 \pi}\left(\int_{|a| \leq t} P\left(r, t e^{i(\theta-\alpha)}\right) d \mu(a)\right)^{q} d \theta\right\}^{1 / q} \\
& \leq \int_{0}^{r} \frac{d t}{t} \int_{|a| \leq t} d \mu(a)\left\{\frac{1}{2 \pi} \int_{0}^{2 \pi}\left(P\left(r, t e^{i(\theta-\alpha)}\right)\right)^{q} d \theta\right\}^{1 / q} \\
& =\int_{0}^{1} \frac{d \tau}{\tau} \int_{|a| \leq r \tau} d \mu(a)\left\{\frac{1}{2 \pi} \int_{0}^{2 \pi}\left(P\left(1, \tau e^{i(\theta-\alpha)}\right)\right)^{q} d \theta\right\}^{1 / q}, \\
& 0<r<1, \quad 1<q<+\infty, \quad a=|a| e^{i \alpha} .
\end{aligned}
$$

Note that the inner integrals in this relations do not depend upon $\alpha$. Therefore, taking into consideration the inequality ([13], p. 288)

$$
\left\{\frac{1}{2 \pi} \int_{0}^{2 \pi}\left(P\left(1, t e^{i x}\right)\right)^{q} d x\right\}^{1 / q} \leq A_{q}^{\prime}(1-t)^{-1 / q^{\prime}}, \quad 1<q<+\infty
$$


where $1 / q+1 / q^{\prime}=1, A_{q}^{\prime}$ is some positive constant, we get that

$$
m_{q}(r, p) \leq A_{q}^{\prime} \int_{0}^{1}(1-t)^{-1 / q^{\prime}} n(r t, B) t^{-1} d t, \quad 0<r<1
$$

which, in combination with (2.8), gives

$$
\begin{gathered}
m_{q}(r, \log B) \leq A_{q}\left(1+C_{q}\right)(1-r)^{-1 / q^{\prime}} \int_{r}^{1} n(t, B) t^{-1} d t \\
+A_{q}^{\prime} C_{q} \int_{0}^{1}(1-t)^{-1 / q^{\prime}} n(r t, B) t^{-1} d t, \\
0<r<1, \quad 1<q<+\infty .
\end{gathered}
$$

Then the statement of the theorem follows from its assumptions, the monotony of the function $n(r, B)$, the relations

$$
\begin{gathered}
(1-r)^{-1 / q^{\prime}} \int_{r}^{1} n(t, B) t^{-1} d t \leq \int_{r}^{1}(1-t)^{-1 / q^{\prime}} n(t, B) t^{-1} d t \\
(1-t)^{-1 / q^{\prime}} n(t, B)=O\left((1-t)^{-1} l(t)\right), \quad t \rightarrow 1
\end{gathered}
$$

and the inequality (2.9).

The Blaschke products, for which (2.1) follows from the boundedness of $m_{q}(r, \log B)$, with some positive on $(0,1)$ function $l$ satisfying the relation (2.2), will be considered in the separate paper of the first author of the present work.

\section{CONCLUSION}

The results of MacLane and Rubel [9], Linden [7; 8], Yeyko and Kondratyuk [12] characterizing the behaviour of the logarithmic means of Blaschke products are generalized. The main result is Theorem 2.1. The proof is based on the M. Riesz theorem on conjugate functions and a new representation of the considered branch of argument of the Blaschke product.

\section{REFERENCES}

[1] E.M. Dyn'kin. Metody teorii singuliarnyh integralov. (preobrazobanie Gil'berta i teorija Kal'derona-Zigmunda). Itogi nauk i tekhniki. Sovremen. problemy mat. Fundam. naprav. / VINITI, 197 - 292, 1987. (in Russian)

[2] P. Edwards. Riady Fur'e v sovremennom izlozhenii 2. M.: Mir, 1985. (in Russian) 
[3] Dzh. Garnett. Ogranichennye analiticheskie funkcii. 1984. (in Russian)

[4] U. Heiman. Meromorfnye funkcii. M.: Mir, 1966. (in Russian)

[5] R.Z. Kalinec and A.A. Kondratyuk. Pro reguliarnist' zrostannia modulia i argumenta ciloi funkcii $\vee l^{p}[0,2 \pi]$-metryci. Ukr. mat. zhur., 50(7), $889-896,1998$. (in Ukrainian)

[6] A.A. Kondratyuk. Riady Fur'e i meromorfnye funkcii. L'vov: Vyscha shkola, 1988. (in Russian)

[7] C.N. Linden. On Blaschke products of restricted growth. Pacific J. Math., 38, 501 $513,1971$.

[8] C.N. Linden. Integral means and zero distributions of Blaschke products. Canadian J. Math., 24, 755 - 760, 1972.

[9] G.R. MacLane and L.A. Rubel. On the growth of the Blaschke products. Canadian J. Math., 21, 595 - 600, 1969.

[10] L.A. Rubel. Entire and meromorphic functions. Springer, 1996.

[11] L.A. Rubel and B.A. Taylor. A Fourrier series method for meromorphic and entier functions. Bull. Soc. Math. France, 96, 53 - 96, 1968.

[12] V.Yeyko and A. Kondratyuk. Ob integral'nych logarifmicheskih srednik proizvedeniy Blaschke. Mat. zametki, 64, 199 - 206, 1998.

[13] A. Zigmund. Trigonometricheskie riady 1. M.: Mir, 1965. (in Russian)

\section{Apie Blaschke sandaugos logaritmų integralinių reikšmių aprèžtumą}

Ya. Vasylkiv, A. Kondratyuk, S. Tarasyuk

Šiame straipsnyje Furje eilučių metodu gauta analitinių funkcijų Blaschke sandaugos logaritmų integralinių reikšmių elgsenos charakteristika. Jeigu Blaschke sandaugos $B$ nulių funkcija $n(r, B)$ tenkina sąlygą $n(r, B)=O\left((1-r)^{-1 / q} l(r)\right), \quad r \rightarrow 1, \quad q>1$, čia $l$ yra neneigiama funkcija intervale $(0,1)$ ir $\int_{0}^{1} \frac{l(t)}{1-t} d t<+\infty$, tuomet $q$-integralinè reikšmè

$m_{q}(r, \log B)=\left\{\frac{1}{2 \pi} \int_{0}^{2 \pi}\left|\log B\left(r e^{i \theta}\right)\right|^{q} d \theta\right\}^{1 / q}$ yra aprèžta intervale $(0,1)$, kai $\log B$ yra $B$ logaritmo šaka. 